\title{
Epithelial-mesenchymal transition in cancer: Role of the IL-8/IL-8R axis (Review)
}

\author{
ZHIWEI ZHAO $^{1 *}$, SHICHAO WANG ${ }^{1,2^{*}}$, YINGBO LIN $^{3}$, YALI MIAO ${ }^{4}$, YE ZENG $^{1}$, \\ YONGMEI NIE ${ }^{2}$, PENG GUO $^{1}$, GUANGYAO JIANG $^{5}$ and JIANG WU ${ }^{1,2}$ \\ ${ }^{1}$ West China Medical Center, Sichuan University, Chengdu, Sichuan 610041; \\ ${ }^{2}$ School of Basic Medicine, Xinjiang Medical University, Urumqi, Xinjiang 830011, P.R. China; \\ ${ }^{3}$ Department of Oncology and Pathology, Karolinska Institute, Cancer Centre Karolinska, \\ SE-171 76 Stockholm, Sweden; ${ }^{4}$ West China Second University Hospital, Sichuan University; \\ ${ }^{5}$ Outpatient Building, West China Fourth Hospital, Sichuan University, Chengdu, Sichuan 610041, P.R. China
}

Received January 26, 2016; Accepted January 19, 2017

DOI: $10.3892 / \mathrm{ol} .2017 .6034$

\begin{abstract}
Epithelial-mesenchymal transition (EMT) is a biological process that is associated with cancer metastasis and invasion. In cancer, EMT promotes cell motility, invasion and distant metastasis. Interleukin (IL)- 8 is highly expressed in tumors and may induce EMT. The IL-8/IL-8R axis has a vital role in EMT in carcinoma, which is regulated by several signaling pathways, including the transforming growth factor $\beta$-spleen associated tyrosine kinase/Src-AKT/extracellular signal-regulated kinase, p38/Jun N-terminal kinase-activating transcription factor-2, phosphoinositide 3-kinase/AKT, nuclear factor- $\kappa \mathrm{B}$ and Wnt signaling pathways. Blocking the IL-8/IL-8R signaling pathway may be a novel strategy to reduce metastasis and improve patient survival rates. This
\end{abstract}

Correspondence to: Dr Jiang Wu, West China Medical Center, Sichuan University, 17 Section 3 Renmin South Road, Chengdu, Sichuan 610041, P.R. China

E-mail: jw@scu.edu.cn

Dr Guangyao Jiang, Outpatient Building, West China Fourth Hospital, Sichuan University, 18 3rd Section, Renmin Nanlu Road, Chengdu, Sichuan 610041, P.R. China

E-mail: 502422662@qq.com

${ }^{*}$ Contributed equally

Abbreviations: EMT, epithelial-mesenchymal transition; MET, mesenchymal-epithelial transition; IL-6, interleukin-6; IL-8, interleukin-8; VEGF, vascular endothelial growth factor; TGF $\beta$, transforming growth factor $\beta$; MMP, matrix metalloprotease; TNF $\alpha$, tumor necrosis factor- $\alpha$; PTEN, phosphatase and tensin homolog; PI3K, phosphatidyl inositol 3-kinase; JNK, Jun N-terminal kinase; ATF-2, activating transcription factor-2; NF- $\kappa \mathrm{B}$, nuclear factor- $\kappa \mathrm{B}$

Key words: interleukin-8, C-X-C motif chemokine receptor 1, $\mathrm{C}-\mathrm{X}-\mathrm{C}$ motif chemokine receptor 2, epithelial-mesenchymal transition, metastasis, prognosis review will cover IL-8-IL-8R signaling pathway in tumor epithelial-mesenchymal transition.

\section{Contents}

1. Introduction

2. EMT and tumorigenesis

3. Regulation of EMT

4. Signaling pathways associated with IL-8

5. Effects of IL-8 on EMT in the tumor microenvironment

6. Prognosis

7. Conclusion

\section{Introduction}

Epithelial-mesenchymal transition (EMT) is a crucial process that promotes cell motility, wound healing, tissue regeneration, fibrogenesis and tumor metastasis (1). EMT has been reported to be implicated in multiple steps of several developmental processes involved in tumor progression (2). It can lead to a loss of cell-cell junctions in tumor cells and a decrease in the expression of E-cadherin in the epithelium (3). EMT can also lead to an increase in expression of vimentin (4), a marker of mesenchymal-derived cells. Notably, EMT facilitates cancer cells to initiate distant metastasis and is able to increase motility of cancer cells at the leading tumor edge and cell invasion (5). EMT is an important process in cancer cell migration and invasion. Thus, manipulating the EMT process in vivo may be a useful strategy to prevent tumor metastasis. Notably, the cytokine interleukin (IL-8) is important for EMT, and it is highly expressed in the cancer microenvironment (6). Although IL-8 has a pro-inflammatory role, cancer cells are able to evade host immune defense mechanisms (7). The chemokine IL- 8 is secreted by fibroblasts, endothelial and immune cells. IL-8 expression is closely associated with cancer (6). Furthermore, the involvement of IL-8 in angiogenesis (8), and cancer cell invasion and metastasis has been previously 
reported (9). A previous study has indicated that in cancer patients, increased expression of IL-8 in tumor tissues may be associated with EMT (10).

\section{EMT and tumorigenesis}

It has been previously demonstrated that EMT in tumors can be induced by the secretion of specific factors, including IL-6, IL-8, vascular endothelial growth factor (VEGF), transforming growth factor $\beta$ (TGF $\beta$ ), SNAIL, matrix metalloprotease (MMP), tumor necrosis factor $\alpha(\mathrm{TNF} \alpha)$ and TWIST (2,11-14). The secretion of pro-inflammatory cytokines (TNF $\alpha$ and IL-6), chemokine IL-8 and growth factors (TGF $\beta$ and VEGF) has also been reported in A549 cells, and may have important associations with cancer (2). IL-8 is able to promote cell motility, cancer metastasis and cell invasion (15) following EMT. Tumor cells are able to secrete IL-8 via an autocrine mechanism, which can promote EMT. A previous study revealed that knockdown of IL-8 suppressed the level of phosphorylated AKT in S18 cells (4). IL-8 knockdown may lead to upregulation of the epithelial marker E-cadherin as well as downregulation of the mesenchymal markers vimentin and fibronectin (4). Additionally, IL-8 has been closely associated with EMT (16) and may promote tumor metastasis and cell invasion.

Cancer cells undergo a reversal of EMT, termed mesenchymal-epithelial transition (MET) (17), to invade multiple organs until they migrate to their final destination for colonization. In contrast to EMT, MET is associated with colonization at the metastatic site (18). Once mesenchymal cells reach their destination, the cell phenotype changes to an epithelial phenotype via MET to colonize the organs (19). These changes involve the loss of cell-cell junctions, and cells acquire motility and invasive capabilities (3). Cancer cells must undergo the MET process to migrate to their destination. Furthermore, MET is closely associated with cancer cells, which may acquire a second colonization (otherwise termed metastasis).

A vital characteristic of cancer metastasis is induction of EMT, which is associated with interaction with the extracellular matrix (20). In the extracellular matrix, the role of the cellular factors is to communicate with the intracellular matrix and a number of these factors have been reported to be associated with EMT, including IL-6, IL-8, VEGF, TGF $\beta$, SNAIL, MMP, TNF $\alpha$ and TWIST. The mechanism underlying the interaction between these factors and EMT is complicated. Notably, the dramatic phenotypic change in EMT is coupled with motility and metastasis (21). Understanding the underlying mechanisms involved in normal morphogenesis and designing treatment strategies to reduce EMT is vital (17).

During the EMT process, cancer cells lose cell polarity and adhesion. The cancer cells acquire increased migratory and invasive capabilities. The EMT process is regulated by several signaling pathways $(22,23)$, which lead to cancer cell migration and invasion. In breast cancer, cancer cells penetrate and transmigrate into the basement membrane barriers, causing angiogenesis and invasion (24) into the circulation. It has been observed that when EMT was activated by epithelial cells in the epithelium constituent of carcinosarcomas, the cells exhibited epithelial and mesenchymal phenotype (25). Furthermore, the study was able to directly assess epithelial plasticity and EMT reversal.

The EMT in carcinoma allows cancer cells to gain increased motility and invasiveness. EMT involves a change in phenotype from epithelial to mesenchymal, thereby allowing cells to invade and colonize nearby tissues. Disseminated cancer cells need to transmigrate the epithelial status during the period of metastatic colonization. These cancer cells have high proliferative potential, allowing the formation of secondary tumors. The normal cellular junctions consist of specific epithelial splicing and epigenetic mechanisms to maintain epithelial homeostasis (25). In summary, EMT is regulated by many factors in the extracellular and intracellular matrix. It has a vital role in regulating cancer cell motility, metastasis, invasion, reverse transition and establishment of a secondary tumor.

\section{Regulation of EMT}

Transforming growth factor $\beta$ (TGF $\beta)$. E-cadherin and vimentin are markers of epithelial and mesenchymal cells, respectively (6). It has been previously demonstrated in A549 human lung carcinoma cell line that a number of cytokines are associated with EMT, including IL-8, VEGF, TGF $\beta$ and $\mathrm{TNF} \alpha$ (26). It has also been reported that TGF $\beta$ is able to induce EMT in multiple cell lines via activation of the E-cadherin repressor (19). Bone morphogenetic protein 7 is a member of the transforming growth factor- $\beta$ family and serves an important role in kidney development (27). TGF $\beta$ has an important role in cell migration and is a tumor-promoting factor. It has also been reported that TGF $\beta$ is able to upregulate MMP expression in A549 lung cancer cells. TGF $\beta$ is able to induce EMT to promote metastasis (28). Other studies have also revealed that TGF $\beta$ is able to induce EMT by upregulating the expression of zinc finger E-box binding homeobox 1 (ZEB1) in renal tubular epithelial cells (29). Epstein-Barr virus-induced TGF $\beta$-spleen associated tyrosine kinase (Syk)/Src AKT/extracellular signal-regulated kinase (ERK) signaling may also be able to promote malignant and invasive potential in human corneal epithelial cells by inducing EMT, and thus may be an effective therapeutic target for the treatment of ocular disease (30). Therefore, the TGF $\beta$ signaling pathway may have an important role in advancing tumor progression and metastasis.

MMPs. The role of MMPs in cell invasion and tumor metastasis has been well established. MMPs are able to remodel the cell cytoskeleton in tumor cells to induce EMT. It has been demonstrated that MMP-2 is able to facilitate tumor metastasis and cell invasion. MMP-2 may therefore be a sensitive predictor of lung tumor progression (31). Furthermore, MMPs released by tumor-associated neutrophils, may facilitate tumor progression, leading to cytoskeleton remodeling and promotion of tumor metastasis (32). Therefore, MMPs may have an important role in tumor metastasis and thus may provide a novel target for cancer therapeutics.

SNAIL. Previous studies have suggested that SNAIL has an important role in EMT in cancer cells, particularly in epithelial tumor cells $(33,34)$. SNAIL is able to reduce the number of cell-cell junctions in cancer tissue and alter the cell 
cytoskeleton (35). SNAIL, vimentin and TWIST are upregulated in human hepatic cells, and these changes are associated with EMT (13). It has also been demonstrated that SNAIL is able to directly activate IL-8 via binding with the IL-8 receptor (36). EMT is promoted by the expression of Notch, which leads to E-cadherin activation via SNAIL (37-39). Additionally, a previous study suggested that high expression of Notch leads to EMT (40). Notably, SNAIL-induced EMT can be eliminated by anti-IL- 8 receptor B neutralizing antibodies, suggesting that IL-8 has an effective role in mediating SNAIL-induced EMT and in advancing carcinoma development (41). Targeting IL-8 may provide a novel strategy for the treatment of cancer. Previous studies have also revealed close associations between EMT and SNAIL in tumor metastasis (42-44). ZEB1, TWIST and SNAIL have also been implicated in carcinoma via the phosphatidyl inositol 3-kinase (PI3K) $(45,46)$ and glycogen synthase kinase $3 \beta$ signaling pathways (42).

$V E G F$. A previous study demonstrated that IL-6 (47) and VEGF (48) cytokines are secreted by neoplastic cells undergoing EMT. Furthermore, it has been reported that these two cytokines can co-operate to induce EMT (2) in prostate intraepithelial neoplasia-like cells via an autocrine loop (48). MCF7 breast cancer cells are also able to undergo EMT via TWIST overexpression, and this was associated with increased synthesis of the angiogenic factor VEGF (49). VEGF has an important role in angiogenesis, thus VEGF and microvessel density may be useful biomarkers for predicting outcomes for colorectal cancer patients (50). In summary, VEGF has a vital role in cancer progression by promoting EMT via angiogenesis.

$I L-8$ and $I L-8 R$. It has been reported that the levels of IL-8 and IL- 8 receptor type 1 (CXCR1) and 2 (CXCR2) increase due to the inhibition of phosphatase and tensin homolog (PTEN) in prostate carcinoma $(51,52)$. Overexpression of CXCR1 and CXCR2 has been detected in prostate cancer tissue and promotes tumor progression by contributing to cell proliferation and angiogenesis (52). Furthermore, overexpression of IL-8 and CXCR2 has been closely associated with tumor progression and metastasis in esophageal squamous cell carcinoma (53). IL-8 may induce tumor progression, metastasis and angiogenesis via CXCR2 (54). The role of microRNA-200 in inhibiting angiogenesis via downregulation of IL-8 and CXCR1 in ovarian cancer cell lines has also been reported (55). The expression of CXCR1 and CXCR2 was not affected by chemotherapy in breast cancer where there was increased expression of IL-8, thus CXCR may be desensitized prior to and following chemotherapy (56). IL-8 and CXCL1 can affect angiogenesis via endothelial CXCR2 receptors (57). In summary, IL-8 and its receptors are closely associated with tumor progression, angiogenesis and metastasis, which may promote EMT in tumor cells.

Blocking IL-8 signaling is a potential strategy to inhibit EMT and thus reduce tumor progression, metastasis and angiogenesis, which may lead to improvements in 5-year disease-free survival and overall survival rates (11). There is increased expression of IL-8 in the tumor microenvironment. IL- 8 secretion may be mediated via fibroblasts, endothelial cells and immune cells, which may promote EMT in cancer (11).

\section{Signaling pathways associated with IL-8}

The p38/Jun N-terminal kinase (JNK)-activating transcription factor-2 (ATF-2) signaling pathway serves a vital role in cell invasion and EMT, which is mediated by autocrine IL-8 in A549 lung cancer cells (2). Previous studies have demonstrated that ATF-2 is able to promote tumorigenesis, and has been observed to be upregulated in various types of carcinoma, including mouse skin tumors (58), human neuroblastoma (59) and prostatic neoplasia (60). Notably, ATF-2 can be activated by IL- 8 transcription (61). IL- 8 is able to induce the JNK/p38-ATF-2 signaling pathway and promote invasion in A549 lung cancer cells (2). Furthermore, ATF-2 is a potential therapeutic target for inhibiting tumor metastasis (2).

The PI3K/AKT signaling pathway has an important role in promoting cell proliferation and survival. Inhibiting the AKT signaling pathway can lead to a decrease in cell motility, which is induced by IL-8 stimulation. AKT is an important signaling pathway for modulating IL-8-induced cell motility and invasion (62). PTEN can result in dysregulation of the PI3K/AKT signaling axis in pancreatic ductal adenocarcinoma (63). Furthermore, loss of PTEN induces the upregulation of IL-8 signaling in prostate carcinoma (51). A previous study has demonstrated that there is high expression of phosphorylated AKT when cells are treated with recombinant human netrin-1 in a human hepatocellular carcinoma cell line (64). The role of AKT in activating nuclear factor $(\mathrm{NF})-\kappa \mathrm{B}$ signaling has been well established (65). Additionally, the NF- $\mathrm{B}$ signaling pathway has been associated with IL-8, which has an important function in regulating tumor invasion (66). Therefore, cell motility can be promoted by IL- 8 via the AKT signaling pathway. It has also been reported that AKT signaling can lead to EMT in breast cancer cells (67).

Several signaling pathways have been associated with EMT, including the PI3K and Wnt signaling pathways (68). The Wnt signaling pathway can be activated via overexpression of IL-8 (69). Previous studies have also indicated that the Wnt signaling pathway serves an important role in mediating cell-cell adhesion and beta-catenin self-phosphorylation in tumor cells $(70,71)$. Therefore, the PI3K/AKT, NF- $\mathrm{B}$ and Wnt signaling pathways are closely associated with IL-8 and EMT $(62,72)$. The signaling pathways and factors associated with EMT in tumor cell proliferation, metastasis, invasion and angiogenesis are displayed in Table I (11,12,14,73-83).

\section{Effects of IL-8 on EMT in the tumor microenvironment}

The cytokine IL- 8 is a potential therapeutic target for treating inflammatory diseases $(84,85)$ and inhibiting carcinoma angiogenesis (86). A previous study has demonstrated that IL-8 mRNA expression has a role in EMT and tumor progression (87). In prostate carcinoma cells, increased expression of IL-8 promotes cancer progression, but the expression of E-cadherin is reduced. In addition, IL-8 has an important role in cancer cell proliferation, invasion and metastasis (62). Cancer cells secrete IL-8, and promote angiogenesis, cell proliferation, metastasis and invasion (62). Under hypoxic conditions, cancer cells are able to secrete IL-8 (78). Additionally, the 
Table I. Epithelial-mesenchymal transition in tumors is closely associated with several cytokines.

\begin{tabular}{lll}
\hline Factors & Associated signaling pathways & Associations with tumor \\
\hline IL-8 & p38/JNK-ATF-2 (2) & Induction of EMT (11) \\
& PI3K/AKT (73) & Angiogenesis (75) \\
& NF-kB $(66,74)$ & Promotion of cancer cell proliferation, \\
& invasion and metastasis (76)
\end{tabular}

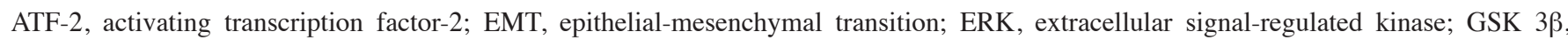
glycogen synthase kinase 3 $\beta$; IL-8, interleukin-8; PI3K, phosphatidyl inositol 3-kinase; JNK, Jun N-terminal kinase; NF-кB, nuclear factor-кB; MMP, matrix metalloprotease; Syk, spleen associated tyrosine kinase; TGF $\beta$, transforming growth factor $\beta$; VEGFR, vascular endothelial growth factor receptor.

expression of IL-8 in various types of carcinoma tissues, including breast, colon, gastric, lung and ovarian cancer has also been reported (88). IL-8 secretion is induced by TGF $\beta$ stimulation (79) and SNAIL overexpression (36), which can lead to EMT in colorectal cancer cells.

IL-8 can induce and maintain the mesenchymal phenotype to facilitate metastatic carcinoma progression. Previous studies have reported that IL- 8 secreted by the tumor stroma is able to induce cell proliferation (89), migration, invasion and EMT $(11,79,90)$. These factors may enable cancer cells to evade apoptosis, and thus promote cell survival (91). IL-8 is also able to induce angiogenesis (92-94), and facilitate cancer progression and metastasis in melanoma and ovarian cancer $(95,96)$. Increased serum levels of IL-8 are associated with the risk of lung cancer, which precedes diagnosis (77). Furthermore, a previous study has demonstrated that the blockade of CXCR1 with a CXCR1-specific blocking antibody or repertaxin, the small-molecule inhibitor of IL-8, was able to inhibit angiogenesis, invasion, metastasis and tumor progression in xenograft tumor models $(97,98)$. IL-8 is able to promote cell migration, invasion, and metastasis (72). IL- 8 also serves a vital role in EMT and can regulate the tumor microenvironment (6). In summary, there are close associations between IL-8 and EMT in cancer. A list of the signaling pathways and factors associated with IL-8, including PI3K/AKT, NF-кB, p38/ATF-2, JNK, MMP and Wnt signaling pathways are displayed in Fig. 1.

Increased expression of IL- 8 in the tumor microenvironment is associated with cell invasion and metastasis. IL- 8 may

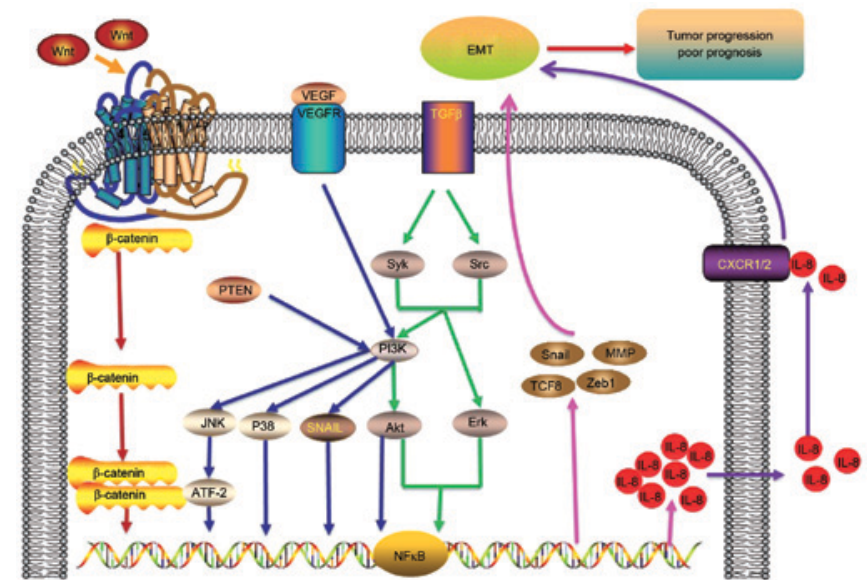

Figure 1. IL-8/IL-8R axis. IL-8 is able to induce EMT and promote tumor progression. There are important associations between IL-8/IL-8R and EMT in cancer patients. The IL-8/IL-8R signaling pathway is able to induce IL-8 overexpression, which is closely correlated with poor prognosis. ATF-2, activating transcription factor-2; CXCR1/2, IL-8 receptor type $1 / 2$; EMT, epithelial-mesenchymal transition; ERK, extracellular signal-regulated

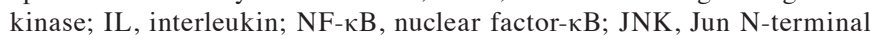
kinase; MMP, matrix metalloprotease; PI3K, phosphatidyl inositol 3-kinase; PTEN, phosphatase and tensin homolog; Syk, spleen associated tyrosine kinase; TGF $\beta$, transforming growth factor $\beta$; VEGFR, vascular endothelial growth factor receptor; ZEB1, zinc finger e-box binding homeobox 1.

have an important role in ovarian cancer metastasis and induces EMT (99). Another study also reported the important role of a number of cytokines including IL-8 in tumor metastasis (100). 
Furthermore, invasive tumor cells have increased expression of IL-8 compared with non-cancerous tissue cells (101). Tumor cells can promote cell motility when there is an increased expression of IL-8 in the tumor microenvironment, thus promoting cancer cell migration and metastasis (102). The expression of the brachyury gene is positively associated with IL-8 and negatively associated with E-cadherin. This may lead to induction of EMT and tumor metastasis in primary lung cancer (103). Studies generally have reported that EMT can be induced by IL-8, which promotes cancer metastasis and angiogenesis $(6,11)$. However, IL- 8 secretion in the tumor microenvironment can also be induced by EMT.

\section{Prognosis}

Researchers have observed that IL-8 serves an important role in the prognosis of several types of carcinoma, including breast, colorectal, lung, gastric and prostate cancer (77,104-108). Increased levels of IL-8 and MMP-3 are indicators of poor prognosis in triple-negative breast carcinomas (109). A study demonstrated that NF- $\kappa \mathrm{B}$ upregulates IL-8, which led to tumor progression and poorer outcomes in a pancreatic cancer model (100). Brachyury mRNA is able to induce the secretion of IL-8 and reduce the 5-year disease-free survival and overall survival rates (103). Additionally, the levels of IL-8 and its receptor may be employed as an indictor to predict prognosis and survival rate. Increased levels of IL-8 in ovarian, lung, renal and breast cancer have been reported, and this was associated with poor prognosis (55). Therefore, inhibiting IL-8 may be a potential strategy to control cancer cell migration, invasion and metastasis. Furthermore, IL-8 is able to induce EMT and this leads to a poor outcome in hepatocellular cancer patients (10). In summary, IL-8 has an important association with EMT and prognosis in cancer patients.

\section{Conclusion}

EMT has an important role in the progression of cancer metastasis. Induction of EMT is closely associated with distant metastasis and cell invasion in tumor progression, and indicates a poor prognosis. A number of studies have reported that multiple factors can affect EMT in cancer, including IL-6, IL-8, VEGF, TGF $\beta$, SNAIL, MMP, TNF $\alpha$ and TWIST $(30,110,111)$, which can enhance cell motility and promote tumor metastasis. EMT in cancer cells involves loss of cell-cell junctions and the acquisition of cell motility and invasion factors. Multiple signaling pathways are closely associated with EMT in tumors, including TGF $\beta$-Syk/Src-AKT/ERK, p38/JNK-ATF-2, PI3K/AKT, NF- $\kappa$ B and Wnt signaling pathways $(2,30,112-114)$. Additionally, IL-8 and its receptors have associations with EMT in cancer patients, thus blocking the IL-8/IL-8R axis may have be a potential strategy to improve prognosis for cancer patients.

\section{Acknowledgements}

The present study was supported by the National Natural Science Foundation of China (grant no. 11262020) and the Foundation of Sichuan Provincial Science and Technology
Program (grant nos. 2013JY0021, 2014SZ0002-15 and 2016SZ0020).

\section{References}

1. Lee $\mathrm{K}$ and Nelson CM: New insights into the regulation of epithelial-mesenchymal transition and tissue fibrosis. Int Rev Cell Mol Biol 294: 171-221, 2012.

2. Desai S, Laskar S and Pandey BN: Autocrine IL-8 and VEGF mediate epithelial-mesenchymal transition and invasiveness via p38/JNK-ATF-2 signalling in A549 lung cancer cells. Cell Signal 25: 1780-1791, 2013.

3. Nieto MA: The ins and outs of the epithelial to mesenchymal transition in health and disease. Annu Rev Cell Dev Biol 27: 347-376, 2011.

4. Li XJ, Peng LX, Shao JY, Lu WH, Zhang JX, Chen S, Chen ZY, Xiang YQ,Bao YN,Zheng FJ, et al: As an independent unfavorable prognostic factor, IL-8 promotes metastasis of nasopharyngeal carcinoma through induction of epithelial-mesenchymal transition and activation of AKT signaling. Carcinogenesis 33: 1302-1309, 2012.

5. Mathias RA, Gopal SK and Simpson RJ: Contribution of cells undergoing epithelial-mesenchymal transition to the tumour microenvironment. J Proteomics 78: 545-57, 2013.

6. Palena C, Hamilton DH and Fernando RI: Influence of IL-8 on the epithelial-mesenchymal transition and the tumor microenvironment. Future Oncol 8: 713-722, 2012.

7. Malmberg KJ and Ljunggren HG: Escape from immune- and nonimmune-mediated tumor surveillance. Semin Cancer Biol 16: 16-31, 2006

8. Koch AE, Polverini PJ, Kunkel SL, Harlow LA, DiPietro LA, Elner VM, Elner SG and Strieter RM: Interleukin-8 as a macrophage-derived mediator of angiogenesis. Science 258: 1798-1801, 1992.

9. Bhusari PA and Khairnar KB: Greater omental pancake tumour due to metastasis of ovarian cancer-a cadaveric study. J Clin Diagn Res 8: 142-143, 2014.

10. Yu J, Ren X, Chen Y, Liu P, Wei X, Li H, Ying G, Chen K, Winkler $\mathrm{H}$ and Hao $\mathrm{X}$ : Dysfunctional activation of neurotensin/IL-8 pathway in hepatocellular carcinoma is associated with increased inflammatory response in microenvironment, more epithelial mesenchymal transition in cancer and worse prognosis in patients. PLoS One 8: e56069, 2013.

11. Fernando RI, Castillo MD, Litzinger M, Hamilton DH and Palena C: IL-8 signaling plays a critical role in the epithelial-mesenchymal transition of human carcinoma cells. Cancer Res 71: 5296-5306, 2011.

12. Islam SS, Mokhtari RB, El Hout Y, Azadi MA, Alauddin M, Yeger $\mathrm{H}$ and Farhat WA: TGF- $\beta 1$ induces EMT reprogramming of porcine bladder urothelial cells into collagen producing fibroblasts-like cells in a Smad2/Smad3-dependent manner. J Cell Commun Signal 8: 39-58, 2014.

13. Bose SK, Meyer K, Di Bisceglie AM, Ray RB and Ray R: Hepatitis $C$ virus induces epithelial-mesenchymal transition in primary human hepatocytes. J Virol 86: 13621-13628, 2012.

14. Radisky DC, Levy DD, Littlepage LE, Liu H, Nelson CM, Fata JE, Leake D, Godden EL, Albertson DG, Nieto MA, et al: Raclb and reactive oxygen species mediate MMP-3-induced EMT and genomic instability. Nature 436: 123-127, 2005.

15. Ye Y, Liu P, Wang Y, Li H, Wei F, Cheng Y, Han L and Yu J: Neurotensin, a novel messenger to cross-link inflammation and tumor invasion via epithelial-mesenchymal transition pathway. Int Rev Immunol 35: 340-350, 2016.

16. Zhou N, Lu F, Liu C, Xu K, Huang J, Yu D and Bi L: IL-8 induces the epithelial-mesenchymal transition of renal cell carcinoma cells through the activation of AKT signaling. Oncol Lett 12: 1915-1920, 2016

17. Nieto MA: Epithelial plasticity: A common theme in embryonic and cancer cells. Science 342: 1234850, 2013.

18. Hugo H, Ackland ML, Blick T, Lawrence MG, Clements JA, Williams ED and Thompson EW: Epithelial-mesenchymal and mesenchymal-epithelial transitions in carcinoma progression. J Cell Physiol 213: 374-383, 2007.

19. Thiery JP, Acloque H, Huang RY and Nieto MA: Epithelial-mesenchymal transitions in development and disease. Cell 139: 871-890, 2009.

20. Kim MJ, Doh II, Bae GY, Cha HJ and Cho YH: Cell-matrix adhesion characterization using multiple shear stress zones in single stepwise microchannel. Appl Phys Lett 105: 083701, 2016. 
21. Rokavec M, Öner MG, Li H, Jackstadt R, Jiang L, Lodygin D, Kaller M, Horst D, Ziegler PK, Schwitalla S, et al: IL-6R/STAT3/miR-34a feedback loop promotes EMT-mediated colorectal cancer invasion and metastasis. J Clin Invest 124: 1853-1867, 2014.

22. Berx G, Raspé E, Christofori G, Thiery JP and Sleeman JP: Pre-EMTing metastasis? Recapitulation of morphogenetic processes in cancer. Clin Exp Metastasis 24: 587-597, 2007.

23. Yang $\mathbf{J}$ and Weinberg RA: Epithelial-mesenchymal transition: At the crossroads of development and tumor metastasis. Dev Cell 14: 818-829, 2008.

24. Ota I, Li XY, Hu Y and Weiss SJ: Induction of a MT1-MMP and MT2-MMP-dependent basement membrane transmigration program in cancer cells by Snaill. Proc Natl Acad Sci USA 106: 20318-20323, 2009.

25. Sarrio D, Rodriguez-Pinilla SM, Hardisson D, Cano A, Moreno-Bueno G and Palacios J: Epithelial-mesenchymal transition in breast cancer relates to the basal-like phenotype. Cancer Res 68: 989-997, 2008

26. Desai S, Kumar A, Laskar S and Pandey BN: Cytokine profile of conditioned medium from human tumor cell lines after acute and fractionated doses of gamma radiation and its effect on survival of bystander tumor cells. Cytokine 61: 54-62, 2013.

27. Dudley AT, Lyons KM and Robertson EJ: A requirement for bone morphogenetic protein-7 during development of the mammalian kidney and eye. Genes Dev 9: 2795-2807, 1995.

28. Illman SA, Lehti K, Keski-Oja J and Lohi J: Epilysin (MMP-28) induces TGF-beta mediated epithelial to mesenchymal transition in lung carcinoma cells. J Cell Science 119: 3856-3865, 2006

29. Xiong M, Jiang L, Zhou Y, Qiu W, Fang L, Tan R, Wen P and Yang J: The miR-200 family regulates TGF- $\beta 1$-induced renal tubular epithelial to mesenchymal transition through Smad pathway by targeting ZEB1 and ZEB2 expression. Am J Physio Renal Physiol 302: F369-F379, 2012.

30. Park GB, Kim D, Kim YS, Kim S, Lee HK, Yang JW and Hur DY: The Epstein-Barr virus causes epithelial-mesenchymal transition in human corneal epithelial cells via Syk/src and Akt/Erk signaling pathways. Invest Ophthalmol Vis Sci 55: 1770-1779, 2014.

31. Guo CB, Wang S, Deng C, Zhang DL, Wang FL and Jin XQ: Relationship between matrix metalloproteinase 2 and lung cancer progression. Mol Diagn Ther 11: 183-192, 2007.

32. Gregory AD and Houghton AM: Tumor-associated neutrophils: New targets for cancer therapy. Cancer Res 71: 2411-2416, 2011.

33. Fang S, Yu L, Mei H, Yang J, Gao T, Cheng A, Guo W, Xia K and Liu G: Cisplatin promotes mesenchymal-like characteristics in osteosarcoma through Snail. Oncol Lett 12: 5007-5014, 2016.

34. Alba-Castellon L, Olivera-Salguero R, Mestre-Farrera A, Pena R, Herrera M, Bonilla F, Casal JI, Baulida J, Peña C and García de Herreros A: Snaill-dependent activation of cancer-associated fibroblast controls epithelial tumor cell invasion and metastasis. Cancer Res 76: 6205-6217, 2016.

35. Haraguchi M, Sato M and Ozawa M: CRISPR/Cas9n-mediated deletion of the Snail 1Gene (SNAI1) reveals its role in regulating cell morphology, cell-cell interactions and gene expression in ovarian cancer (RMG-1) cells. PLoS One 10: e0132260, 2015.

36. Hwang WL, Yang MH, Tsai ML, Lan HY, Su SH, Chang SC, Teng HW, Yang SH, Lan YT, Chiou SH and Wang HW: SNAIL regulates interleukin- 8 expression, stem cell-like activity and tumorigenicity of human colorectal carcinoma cells. Gastroenterology 141: 279-291, 291.e1-e5, 2011.

37. Leong KG, Niessen K, Kulic I, Raouf A, Eaves C, Pollet I and Karsan A: Jagged1-mediated Notch activation induces epithelial-to-mesenchymal transition through Slug-induced repression of E-cadherin. J Exp Med 204: 2935-2948, 2007.

38. Niessen K, Fu Y, Chang L, Hoodless PA, McFadden D and Karsan A: Slug is a direct Notch target required for initiation of cardiac cushion cellularization. J Cell Biol 182: 315-325, 2008

39. Sahlgren C, Gustafsson MV, Jin S, Poellinger L and Lendahl UL: Notch signaling mediates hypoxia-induced tumor cell migration and invasion. Proc Natl Acad Sci USA 105: 6392-6397, 2008

40. Timmerman LA, Grego-Bessa J, Raya A, Bertrén E Pérez-Pomares JM, Díez J, Aranda S, Palomo S, McCormick F, Izpisúa-Belmonte JC and de la Pompa JL: Notch promotes epithelial-mesenchymal transition during cardiac development and oncogenic transformation. Genes Dev 18: 99-115, 2004.

41. Yanagawa J, Walser TC, Zhu LX, Hong L, Fishbein MC, Mah V, Chia D, Goodglick L, Elashoff DA, Luo J, et al: Snail promotes CXCR2 ligand-dependent tumor progression in non-small cell lung carcinoma. Clin Cancer Res 15: 6820-6829, 2009.
42. Liu ZC, Chen XH, Song HX, Wang HS, Zhang G, Wang $\mathrm{H}$, Chen DY, Fang R, Liu H, Cai SH and Du J: Snail regulated by PKC/GSK-3 $\beta$ pathway is crucial for EGF-induced epithelial-mesenchymal transition (EMT) of cancer cells. Cell Tissue Res 358: 491-502, 2014

43. Gras B, Jacqueroud L, Wierinckx A, Lamblot C, Fauvet F, Lachuer J, Puisieux A and Ansieau S: Snail family members unequally trigger EMT and thereby differ in their ability to promote the neoplastic transformation of mammary epithelial cells. PLoS One 9: e92254, 2014.

44. Wettstein G, Bellaye PS, Kolb M, Hammann A, Crestani B, Soler P, Marchal-Somme J, Hazoume A, Gauldie J, Gunther A, et al: Inhibition of HSP27 blocks fibrosis development and EMT features by promoting Snail degradation. FASEB J 27: 1549-1560, 2013

45. Zheng $\mathrm{H}$ and Kang Y: Multilayer control of the EMT master regulators. Oncogene 33: 1755-1763, 2014

46. Zhang J, Zhou Y and Yang Y: CCR7 pathway induces epithelial-mesenchymal transition through up-regulation of Snail signaling in gastric cancer. Med Oncol 32: 467, 2015.

47. Sullivan NJ, Sasser AK, Axel AE, Vesuna F, Raman V, Ramirez N, Oberyszyn TM and Hall BM: Interleukin-6 induces an epithelial-mesenchymal transition phenotype in human breast cancer cells. Oncogene 28: 2940-2947, 2009.

48. Gonzalez-Moreno O, Lecanda J, Green JE, Segura V, Catena R, Serrano D and Calvo A: VEGF elicits epithelial-mesenchymal transition (EMT) in prostate intraepithelial neoplasia (PIN)-like cells via an autocrine loop. Exp Cell Res 316: 554-567, 2010.

49. Mironchik Y, Winnard PT Jr, Vesuna F, Kato Y, Wildes F, Pathak AP, Kominsky S, Artemov D, Bhujwalla Z, Van Diest $\mathrm{P}$, et al: Twist overexpression induces in vivo angiogenesis and correlates with chromosomal instability in breast cancer. Cancer Res 65: 10801-10809, 2005.

50. Wang Y, Yao X, Ge J, Hu F and Zhao Y: Can vascular endothelial growth factor and microvessel density be used as prognostic biomarkers for colorectal cancer? A systematic review and meta-analysis. ScientificWorldJournal 2014: 102736, 2014.

51. Maxwell PJ, Coulter J, Walker SM, McKechnie M, Neisen J, McCabe N, Kennedy RD, Salto-Tellez M, Albanese C and Waugh DJ: Potentiation of inflammatory CXCL8 signalling sustains cell survival in PTEN-deficient prostate carcinoma. Eur Urol 64: 177-88, 2013.

52. Murphy C, McGurk M, Pettigrew J, Santinelli A, Mazzucchelli R, Johnston PG, Montironi R and Waugh DJ: Nonapical and cytoplasmic expression of interleukin-8, CXCR1, and CXCR2 correlates with cell proliferation and microvessel density in prostate cancer. Clin Cancer Res 11: 4117-4127, 2005.

53. Ogura M, Takeuchi H, Kawakubo H, Nishi T, Fukuda K, Nakamura R, Takahashi T, Wada N, Saikawa Y, Omori T, et al: Clinical significance of CXCL-8/CXCR-2 network in esophageal squamous cell carcinoma. Surgery 154: 512-520, 2013.

54. Uzunoglu FG, Yavari N, Bohn BA, Nentwich MF, Reeh M, Pantel K, Perez D, Tsui TY, Bockhorn M, Mann O, et al: C-X-C motif receptor 2 , endostatin and proteinase-activated receptor 1 polymorphisms as prognostic factors in NSCLC. Lung Cancer 81: 123-129, 2013

55. Pecot CV, Rupaimoole R, Yang D, Akbani R, Ivan C, Lu C, Wu S, Han HD, Shah MY, Rodriguez-Aguayo C, et al: Tumour angiogenesis regulation by the miR-200 family. Nat Commun 4: 2427,2013

56. Mendonca MA, Souto FO, Micheli DC, Alves-Filho JC, Cunha FQ, Murta EF and Tavares-Murta BM: Mechanisms affecting neutrophil migration capacity in breast cancer patients before and after chemotherapy. Cancer Chemother Pharmacol 73: 317-324, 2014.

57. Merritt WM, Lin YG, Spannuth WA, Fletcher MS, Kamat AA, Han LY, Landen CN, Jennings N, De Geest K, Langley RR, et al: Effect of interleukin-8 gene silencing with liposome-encapsulated small interfering RNA on ovarian cancer cell growth. J Natl Cancer Inst 100: 359-372, 2008

58. Papassava P, Gorgoulis VG, Papaevangeliou D, Vlahopoulos S, van Dam H and Zoumpourlis V: Overexpression of activating transcription factor-2 is required for tumor growth and progression in mouse skin tumors. Cancer Res 64: 8573-8584, 2004.

59. Tindberg N, Porsmyr-Palmertz $\mathrm{M}$ and Simi A: Contribution of MAP kinase pathways to the activation of ATF-2 in human neuroblastoma cells. Neurochem Res 25: 527-531, 2000.

60. Ricote M, Garcia-Tunon I, Bethencourt F, Fraile B, Onsurbe P, Paniagua $\mathrm{R}$ and Royuela $\mathrm{M}$ : The $\mathrm{p} 38$ transduction pathway in prostatic neoplasia. J Pathol 208: 401-407, 2006. 
61. Eliopoulos AG, Gallagher NJ, Blake SM, Dawson CW and Young LS: Activation of the p38 mitogen-activated protein kinase pathway by Epstein-Barr virus-encoded latent membrane protein 1 coregulates interleukin- 6 and interleukin- 8 production. J Biol Chem 274: 16085-16096, 1999.

62. Wang L, Tang C, Cao H, Li K, Pang X, Zhong L, Dang W, Tang H, Huang Y, Wei L, et al: Activation of IL-8 via PI3K/Akt-dependent pathway is involved in leptin-mediated epithelial-mesenchymal transition in human breast cancer cells. Cancer Biol Ther 16: 1220-1230, 2015.

63. Hill R, Calvopina JH, Kim C, Wang Y, Dawson DW, Donahue TR, Dry S and Wu H: PTEN loss accelerates KrasG12D-induced pancreatic cancer development. Cancer Res 70: 7114-7124, 2010.

64. Yan W, Han P, Zhou Z, Tu W, Liao J, Li P, Liu M, Tian D and Fu Y: Netrin-1 induces epithelial-mesenchymal transition and promotes hepatocellular carcinoma invasiveness. Dig Dis Sci 59: 1213-1221, 2014.

65. Song J, Feng L, Zhong R, Xia Z, Zhang L, Cui L, Yan H, Jia $X$ and Zhang Z: Icariside II inhibits the EMT of NSCLC cells in inflammatory microenvironment via down-regulation of $\mathrm{Akt} / \mathrm{NF}-\kappa \mathrm{B}$ signaling pathway. Mol Carcinog 56: 36-48, 2017.

66. Voorzanger N, Touitou R, Garcia E, Delecluse HJ, Rousset F, Joab I, Favrot MC and Blay JY: Interleukin (IL)-10 and IL-6 are produced in vivo by non-Hodgkin's lymphoma cells and act as cooperative growth factors. Cancer Res 56: 5499-5505, 1996.

67. Carpenter RL, Paw I, Dewhirst MW and Lo HW: Akt phosphorylates and activates HSF-1 independent of heat shock, leading to Slug overexpression and epithelial-mesenchyma transition (EMT) of HER2-overexpressing breast cancer cells. Oncogene 34: 546-557, 2015.

68. Baranwal S and Alahari SK: Molecular mechanisms controlling E-cadherin expression in breast cancer. Biochem Biophys Res Commun 384: 6-11, 2009.

69. Moon HG, Zheng Y, An CH, Kim YK and Jin Y: CCN1 secretion induced by cigarette smoking extracts augments IL-8 release from bronchial epithelial cells. PLoS One 8: e68199, 2013.

70. Cai J, Guan H, Fang L, Yang Y, Zhu X, Yuan J, Wu J and Li M: MicroRNA-374a activates Wnt/ $\beta$-catenin signaling to promote breast cancer metastasis. J Clin Invest 123: 566-579, 2013

71. Zappulli V, De Cecco S, Trez D, Caliari D, Aresu L and Castagnaro M: Immunohistochemical expression of E-cadherin and $\beta$-catenin in feline mammary tumours. J Comp Pathol 147: 161-170, 2012

72. Ahn SH, Park H, Ahn YH, Kim S, Cho MS, Kang JL and Choi YH: Necrotic cells influence migration and invasion of glioblastoma via NF- $\mathrm{B} / \mathrm{AP}-1-$ mediated IL-8 regulation. Sci Rep 6: 24552, 2016.

73. Cheng XS, Li YF, Tan J, Sun B, Xiao YC, Fang XB, Zhang XF, Li Q, Dong JH, Li M, et al: CCL20 and CXCL8 synergize to promote progression and poor survival outcome in patients with colorectal cancer by collaborative induction of the epithelial-mesenchymal transition. Cancer Lett 348: 77-87, 2014.

74. Zhao ZW, Wang YX, Lv X, Nie YM and Wu J: Shear stress promotes epithelial-mesenchymal transition of laryngeal cancer cells by inducing IL-8/CXCR1-NF-Kappa B axis. J Invest Med 62: S80, 2014

75. Choi SH, Kwon OJ, Park JY, Kim DY, Ahn SH, Kim SU, Ro SW, Kim KS, Park JH, Kim S, et al: Inhibition of tumour angiogenesis and growth by small hairpin HIF-1 $\alpha$ and IL-8 in hepatocellular carcinoma. Liver Int 34: 632-642, 2014.

76. Wu S, Shang H, Cui L, Zhang Z, Zhang Y, Li Y, Wu J, Li RK and Xie J: Targeted blockade of interleukin-8 abrogates its promotion of cervical cancer growth and metastasis. Mol Cell Biochem 375: 69-79, 2013.

77. Pine SR, Mechanic LE, Enewold L, Chaturvedi AK, Katki HA, Zheng YL, Bowman ED, Engels EA, Caporaso NE and Harris CC: Increased levels of circulating interleukin 6, interleukin 8, C-reactive protein, and risk of lung cancer. J Natl Cancer Inst 103: 1112-1122, 2011

78. Xie K: Interleukin- 8 and human cancer biology. Cytokine Growth Factor Rev 12: 375-391, 2001.

79. Bates RC, DeLeo MJ III and Mercurio AM: The epithelial-mesenchymal transition of colon carcinoma involves expression of IL-8 and CXCR-1-mediated chemotaxis. Exp Cell Res 299: 315-324, 2004.

80. Yang JR, Pan TJ, Yang H, Wang T, Liu W, Liu B and Qian WH: Kindlin-2 promotes invasiveness of prostate cancer cells via $\mathrm{NF}-\kappa \mathrm{B}$-dependent upregulation of matrix metalloproteinases. Gene 576: 571-576, 2016 .
81. Zucchini-Pascal N, Peyre L and Rahmani R: Crosstalk between beta-catenin and snail in the induction of epithelial to mesenchymal transition in hepatocarcinoma: Role of the ERK1/2 pathway. Int J Mol Sci 14: 20768-20792, 2013.

82. Zhao J, Zhang ZR, Zhao N, Ma BA and Fan QY: VEGF silencing inhibits human osteosarcoma angiogenesis and promotes cell apoptosis via PI3K/AKT signaling pathway. Int J Clin Exp Med 8: 12411-12417, 2015

83. Matsumoto G, Hirohata R, Hayashi K, Sugimoto Y, Kotani E, Shimabukuro J, Hirano T, Nakajima Y, Kawamata S and Mori H: Control of angiogenesis by VEGF and endostatin-encapsulated protein microcrystals and inhibition of tumor angiogenesis. Biomaterials 35: 1326-1333, 2014.

84. Shen Y, Wang D and Wang X: Role of CCR 2 and IL-8 in acute lung injury: A new mechanism and therapeutic target. Expert Rev Respir Med 5: 107-114, 2011.

85. Skov L, Beurskens FJ, Zachariae CO, Reitamo S, Teeling J, Satijn D, Knudsen KM, Boot EP, Hudson D, Baadsgaard O, et al: IL-8 as antibody therapeutic target in inflammatory diseases: Reduction of clinical activity in palmoplantar pustulosis. J Immunol 181: 669-679, 2008.

86. Hatfield KJ, Olsnes AM, Gjertsen BT and Bruserud $\varnothing$ : Antiangiogenic therapy in acute myelogenous leukemia: Targeting of vascular endothelial growth factor and interleukin 8 as possible antileukemic strategies. Curr Cancer Drug Targets 5: 229-248, 2005

87. Li WH, Qiu Y, Zhang HQ, Liu Y, You JF, Tian XX and Fang WG: $\mathrm{P} 2 \mathrm{Y} 2$ receptor promotes cell invasion and metastasis in prostate cancer cells. Br J Cancer 109: 1666-1675, 2013.

88. Waugh DJ and Wilson C: The interleukin-8 pathway in cancer. Clin Cancer Res 14: 6735-6741, 2008.

89. Schadendorf D, Möller A, Algermissen B, Worm M, Sticherling $\mathrm{M}$ and Czarnetzki BM: IL-8 produced by human malignant melanoma cells in vitro is an essential autocrine growth factor. J Immunol 151: 2667-2675, 1993.

90. De Larco JE, Wuertz BR, Rosner KA, Erickson SA Gamache DE, Manivel JC and Furcht LT: A potential role for interleukin-8 in the metastatic phenotype of breast carcinoma cells. Am J Pathol 158: 639-646, 2001.

91. Maxwell PJ, Gallagher R, Seaton A, Wilson C, Scullin P, Pettigrew J, Stratford IJ, Williams KJ, Johnston PG and Waugh DJ: HIF-1 and NF-kappaB-mediated upregulation of CXCR1 and CXCR2 expression promotes cell survival in hypoxic prostate cancer cells. Oncogene 26: 7333-7345, 2007.

92. Lattanzio L, Tonissi F, Torta I, Gianello L, Russi E, Milano G, Merlano M and Lo Nigro C: Role of IL-8 induced angiogenesis in uveal melanoma. Invest New Drugs 31: 1107-1114, 2013.

93. Li KC, Huang YH, Ho CY, Chu CY, Cha ST, Tsai HH, Ko JY, Chang CC and Tan CT: The role of IL-8 in the SDF-1 $\alpha / C X C R 4$-induced angiogenesis of laryngeal and hypopharyngeal squamous cell carcinoma. Oral Oncol 48: 507-515, 2012.

94. Shen XH, Xu SJ, Jin CY, Ding F, Zhou YC and Fu GS Interleukin-8 prevents oxidative stress-induced human endothelial cell senescence via telomerase activation. Int Immunopharmacol 16: 261-267, 2013.

95. Rofstad EK and Halsør EF: Vascular endothelial growth factor, interleukin 8, platelet-derived endothelial cell growth factor, and basic fibroblast growth factor promote angiogenesis and metastasis in human melanoma xenografts. Cancer Res 60: 4932-4938, 2000

96. Shahzad MM, Arevalo JM, Armaiz-Pena GN, Lu C, Stone RL, Moreno-Smith M, Nishimura M, Lee JW, Jennings NB, Bottsford-Miller J, et al: Stress effects on FosB- and interleukin-8 (IL8)-driven ovarian cancer growth and metastasis. J Biol Chem 285: 35462-3547070, 2010

97. Ginestier C, Liu S, Diebel ME, Korkaya H, Luo M, Brown M, Wicinski J, Cabaud O, Charafe-Jauffret E, Birnbaum D, et al: CXCR1 blockade selectively targets human breast cancer stem cells in vitro and in xenografts. J Clin Invest 120: 485-497, 2010.

98. Sparmann A and Bar-Sagi D: Ras-induced interleukin-8 expression plays a critical role in tumor growth and angiogenesis. Cancer Cell 6: 447-458, 2004.

99. Yin J, Zeng F, Wu N, Kang K, Yang Z and Yang H: Interleukin-8 promotes human ovarian cancer cell migration by epithelial-mesenchymal transition induction in vitro. Clin Trans Oncol 17: 365-370, 2015.

100. Kim SW, Hayashi M, Lo JF, Fearns C, Xiang R, Lazennec G, Yang Y and Lee JD: Tid1 negatively regulates the migratory potential of cancer cells by inhibiting the production of interleukin-8. Cancer Res 65: 8784-8791, 2005. 
101. Luca M, Huang S, Gershenwald JE, Singh RK, Reich R and Bar-Eli M: Expression of interleukin- 8 by human melanoma cells up-regulates MMP-2 activity and increases tumor growth and metastasis. Am J Pathol 151: 1105-1113, 1997.

102. Sheridan C, Kishimoto H, Fuchs RK, Mehrotra S, Bhat-Nakshatri P, Turner $\mathrm{CH}$, Goulet R Jr, Badve $\mathrm{S}$ and Nakshatri H: CD44+/CD24- breast cancer cells exhibit enhanced invasive properties: An early step necessary for metastasis. Breast Cancer Res 8: R59, 2006.

103. Haro A, Yano T, Kohno M, Yoshida T, Koga T, Okamoto T, Takenoyama M and Maehara Y: Expression of Brachyury gene is a significant prognostic factor for primary lung carcinoma. Ann Surg Oncol 20 (Suppl 3): S509-S516, 2013

104. Choi J, Song N, Han S, Chung S, Sung H, Lee JY, Jung S, Park SK, Yoo KY, Han W, et al: The associations between immunity-related genes and breast cancer prognosis in Korean women. PLoS One 9: e103593, 2014.

105. Hanker LC, Rody A, Holtrich U, Pusztai L, Ruckhaeberle E, Liedtke C, Ahr A, Heinrich TM, Sänger N, Becker S and Karn T: Prognostic evaluation of the B cell/IL- 8 metagene in different intrinsic breast cancer subtypes. Breast Cancer Res Treat 137: 407-16, 2013.

106. Reitter EM, Ay C, Kaider A, Pirker R, Zielinski C, Zlabinger G and Pabinger I: Interleukin levels and their potential association with venous thromboembolism and survival in cancer patients. Clin Exp Immunol 177: 253-260, 2014.

107. Wang S, Wu X, Zhang J, Chen Y, Xu J, Xia X, He S, Qiang F, Li A, Shu Y, et al: CHIP functions as a novel suppressor of tumour angiogenesis with prognostic significance in human gastric cancer. Gut 62: 496-508, 2013.

108. Manna S, Singha B, Phyo SA, Gatla HR, Chang TP, Sanacora S, Ramaswami S and Vancurova I: Proteasome inhibition by bortezomib increases IL-8 expression in androgen-independent prostate cancer cells: The role of IKK $\alpha$. J Immunol 191: 2837-2846, 2013.
109. Han J, Bae SY, Oh SJ, Lee J, Lee JH, Lee HC, Lee SK, Kil WH, Kim SW, Nam SJ, et al: Zerumbone suppresses IL-1 $\beta$-induced cell migration and invasion by inhibiting IL-8 and MMP-3 expression in human triple-negative breast cancer cells. Phytother Res 28: 1654-1660, 2014.

110. Epanchintsev A, Shyamsunder P, Verma RS and Lyakhovich A: IL-6, IL-8, MMP-2, MMP-9 are overexpressed in Fanconi anemia cells through a NF- $\kappa \mathrm{B} / \mathrm{TNF}-\alpha$ dependent mechanism. Mol Carcinog 54: 1686-1699, 2015.

111. Dong P, Xiong Y, Watari H, Hanley SJ, Konno Y, Ihira K, Yamada T, Kudo M, Yue J and Sakuragi N: MiR-137 and miR-34a directly target Snail and inhibit EMT, invasion and sphere-forming ability of ovarian cancer cells. J Exp Clin Cancer Res 35: 132, 2016.

112. Meng J, Zhang XT, Liu XL, Fan L, Li C, Sun Y, Liang XH, Wang JB, Mei QB, Zhang F and Zhang T: WSTF promotes proliferation and invasion of lung cancer cells by inducing EMT via PI3K/Akt and IL-6/STAT3 signaling pathways. Cell Signal 28: 1673-1682, 2016.

113. Huang T, Chen Z and Fang L: Curcumin inhibits LPS-induced EMT through downregulation of NF- $\kappa \mathrm{B}$-snail signaling in breast cancer cells. Oncol Rep 29: 117-124, 2013.

114. Zhang Z, Chen H, Xu C, Song L, Huang L, Lai Y, Wang Y, Chen $\mathrm{H}, \mathrm{Gu} \mathrm{D}$, Ren L and Yao Q: Curcumin inhibits tumor epithelial-mesenchymal transition by downregulating the Wnt signaling pathway and upregulating NKD2 expression in colon cancer cells. Oncol Rep 35: 2615-2623, 2016. 